\title{
Conservation of the cherry salmon in Taiwan
}

The main range of the cherry salmon

Oncorhynchus masou is the Sea of Japan and adjacent areas, with most populations migrating to spawn in streams in Korea, Japan, the Kuril Islands and the south-west tip of Kamchatka. Landlocked forms of the cherry salmon also occur, among them a relict population in the mountains of Taiwan. This population has declined in recent years and efforts are being made to save it.

Fifty years ago the Taiwanese cherry salmon was widely distributed in the upper tributaries of the Tachia River (Kano, 1940). Today its range and population have declined enormously as a result of development - forestry, roads, reservoirs and agriculture - in the Tachia watershed. It survives only in the Chichiawan stream, one of the upper tributaries of the Tachia (Figure 1).

The species was protected under the Cultural Heritage Preservation Act 1984 and conservation efforts were started. Research to investigate its status, requirements and the condition of its habitat have been ongoing since 1985 . In addition, protective measures were introduced, a restoration programme was initiated and a public education programme was launched.

The population studies revealed that the estimated number of salmon declined from around 1798 in September 1987 (Tsao, 1988) to 918 in July 1990 and if the decline continues at this rate the salmon could be extinct before the end of the century. The declines are probably due to a combination of factors; over-exploitation; population fragmentation due to sandretention dams built on the Chichiawan Stream between 1974 and 1978; natural catastrophes, such as typhoons, which cause landslides and flooding and can seriously disrupt stream habitats; and human disturbances, such as pesticides used on adjacent land belonging to Wuling Farm.

The Cherry Salmon Propagation Centre in Wuiling started with 32 females and 46 males, producing 10,569 eggs in 1986. Of these 7148 survived to the fry stage. By July 1987768 fingerlings survived and 250 of these were tagged and released at three locations on the Chichiawan Stream (Lin and Chang, 1989). Tagged salmon were still seen in the stream until July 1990.

Before the Cultural Heritage Preservation Act in 1984 cherry salmon were caught for food by local people and for sport. When these activities became illegal, patrols were introduced to prevent poaching and to ensure that visitors to the area were informed about the law. Wuling Farm was put in charge of the patrol programme and two people with military dogs are responsible for patrolling the stream and guarding the Cherry Salmon Propagation Centre. Between 1989 and 1990 $\$$ US300,000 were spent on the patrol programme, but the lack of manpower meant that it was not very effective.

The Council of Agriculture (COA) promoted an education programme to increase public

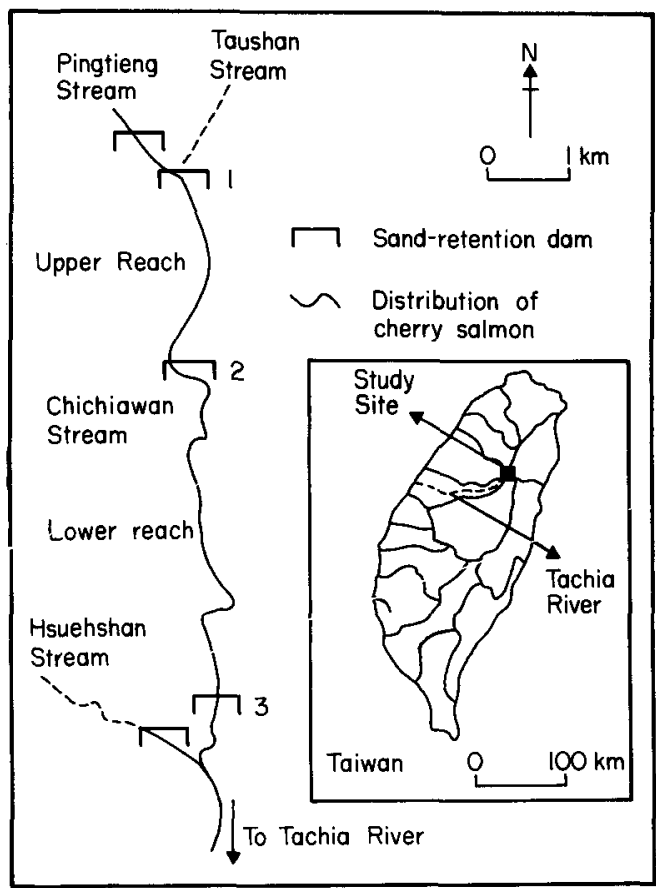

Figure 1. Map of Taiwan and the distribution of cherry salmon. 
awareness of the plight of the salmon. Two videos about its life-history, stream ecology, feeding, breeding behaviour and research and conservation programmes were broadcast at peak viewing time on television and an aquarium containing cherry salmon was set up for visitors to the Cherry Salmon Propagation Centre.

The survival of this cherry salmon depends mainly on maintaining and improving the quality of the stream habitat. This should be tackled at three levels. Firstly, human activities should be prohibited in sensitive and fragile parts of the stream. Secondly, natural vegetation should be planted in a $300-\mathrm{m}$ wide strip on either side of the stream to protect the bank from erosion and to limit the spread of agricultural chemicals. Thirdly, human impacts in the watershed as a whole should be reduced (Chang, 1989).

The COA has already started a project for revegetating a 30 -m-wide strip on either side of the stream. Consideration is also being given as to whether to remove all or some of the sand-retention dams, replacing them with dams that fish can negotiate (Takahashi, 1990).

Artificial propagation would enable salmon stock to be restored if there were severe natural losses in any particular year. Because the hatchery is expensive to run it might be worth considering simply placing fertilized eggs into the stream. At the same time transplanting salmon stock to other streams should be considered to establish new populations.

The Ministry of the Interior has proposed that the Chichiawan stream watershed and Wuling Farm be incorporated into a new national park. Such a move would enhance conservation efforts for the cherry salmon. Land use and tourist activities could be managed in accordance with park regulations and park authorities would have both the capacity and the power to control poaching.

The success of the plans will depend on a tremendous amount of manpower, support from the government and developing public awareness. An education centre is being planned and will be located at Wuling Farm (Lin et al., 1991). The centre will demonstrate conservation efforts for the cherry salmon, the ecology of other Taiwanese freshwater fishes and the development history of the Tachia river.

Yeong-Tyi Day and Yao-Sung Lin Department of Zoology

National Taiwan University, Taipei, Taiwan, ROC. Kun-Hsiung Chang Institute of Zoology, Academica Sinica Taipei, Taiwan, ROC.

\section{Acknowledgments}

We would like to thank the Council of Agriculture, the Republic of China, for funding and Mr Dau-Jay $\mathrm{Lu}$ of the COA for providing many references. We are indebted to Dr Ling-Ling Lee of the National Taiwan University for revising this manuscript.

\section{References}

Chang, X.J. 1989. Planning of the reserve for the cherry salmon (Oncorhynchus masou). Ecol. Res., Council Agr., R.O.C. 1989 No. 10 (in Chinese).

Kano, T. 1940. Zoogeographical Studies of the Tsugitaga Mountain of Formosa. Schibuswa Inst. Ethology Press, Tokyo, $145 \mathrm{pp}$.

Lin, Y.S. and Chang, K.H. 1989. Conservation of the Formosan landlocked salmon Oncorhynchus masou formosanus in Taiwan: a historical review. Physiol. Ecol. Jap., Special. 1, 647-652.

Lin, Y.S., Chang, K.H., Chang C.W. and Chang, Y.W. 1991. Preliminary planning of the education centre for freshwater fish in Wuling. Ecol. Res., Council Agr., R.O.C. 1991. No. 2 .(In Chinese).

Takahashi, G. 1990. On the consistency of conservation of freshwater fish and 'sabo' works in streams. Bull. Inst. Zool., Acad. Sinica, 29 (3), 105-113.

Tsao, S.S. 1988. The Relationship Between Population Distribution and Environmental factors of masu Salmon (Oncorhynchus masou formosanus) in Wu-Ling Farm. M. Sc. Thesis, National Taiwan University, Taipei. 